\title{
Interbank Withdrawal Protocol (IWP): A Complementary System of Rastin Banking
}

\author{
Bijan Bidabad \\ B.A., M.Sc., Ph.D., Post-Doc. \\ Professor \\ Economics and Chief Islamic Banking Advisor \\ Bank Melli, Iran \\ E-mail:bijan@bidabad.com \\ Mahmoud Allahyarifard \\ Senior Expert of Research \\ Planning and Risk Management Department \\ Bank Melli Iran, Tel.: +98.21.88916343 \\ E-mail: Allahyarifard@gmail.com
}

\begin{abstract}
Purpose: This paper aims to define a new protocol, whereby brings the required preparations for the bank to collect its claim or its customer's claim through withdrawal from the debtor's account in other banks and financial institutions that have signed the protocol.

Design: According to this protocol and under central bank supervision, the bank (as owner or attorney of the third party) as claimer of check, promissory note, bill, or a debt initiated by customer's commitment based on collaterals or guarantees, withdraws the claim from the debtor's accounts in other banks and financial institutions that are members of the protocol through Automatic Clearing House (ACH).

Findings: Despite taking collaterals, guarantees, and binding of contracts, executive debt collection process through the legal proceedings is a major challenge that banks, financial institutions, and persons are facing. The legal and execution process of debt collection through collaterals and guarantees are complicated, lengthy, and costly. Interbank Withdrawal Protocol (IWP) solves the problem by proposing a protocol to be accepted by banks to permit withdrawal of the account of the debtor in other banks.

Practical implications: It is seen much that a person owes a lot to a person or bank, but s/he deposits her/his money at her/his accounts in other banks. The Interbank Withdrawal Protocol (IWP) is an agreement between banks which permits the bank to collect the debt through online-withdraw from the accounts of the debtor at other banks after depleting the account of the debtor at the agent bank.

Social implications: This protocol increases reliance and security upon commitments and provides fast settlement and debt collection without time-consuming judicial process. It also reduces judicial proceedings and execution of active files in courts and consequently related costs.

Originality/value: Complementary systems in Rastin Banking have been designed to solve the prevailing problems of banking and financial activities. IWP was designed to provide necessary arrangements for fast, clean debt collection and encashing check and collecting the bill.
\end{abstract}

Keywords: Rastin Banking, Debt Collection, Check Encashing, Bill Collecting, Settlement, Financial Management, Banking Operations.

JEL: L86, L87, G21, G24

\section{Introduction}

In conventional banking, specifically, in those countries that inflation rate is high and executive and judicial processes for debt collection are weak and time-consuming, there are many cases, that a person is indebted a considerable amount to one or some persons/banks but deposits his/her money resources into his/her other accounts in another bank, and performs his/her regular financial transactions just through the latter bank. Consequently, the debts become outstanding claims in former banks, and the claimer has no straightforward and fast way for a clean collection of the debts. Moreover, when the judicial processes are time-consuming and costly, volumes of bounced 
checks are increasing, and too many of the dishonored check issuers keep their money resources in different banks, and the claimer is not able to collect the debt. Legal support of the claimer does not solve the claimer's trouble due to being tedious and costly judicial processes. This subject also causes behavioral exasperation of the debtors to draw rubber checks and fear not to write out the dud checks. Consequently, the average risk increases and production and welfare decline in the economy.

Information and Communication Technology can solve many existing banking problems. Speed, validity, monitoring, controlling, real-time data accessibility are some services that web-based systems provide to banks and their customers as well. In Rastin Banking, ${ }^{1}$ some complementary systems ${ }^{2}$ have been devised that can also be applied in conventional banking as well. Each one of these systems is responsible for solving a particular problem. These systems can be connected to other defined systems to increase financial operations reliability and efficiency. To addressing the difficulties mentioned above, the Interbank Withdrawal Protocol (IWP) system was designed to collect the bank's and its customer's claims from the debtor's account in other banks by using Information and Communication Technology (ICT).

\section{Interbank Withdrawal Protocol (IWP)}

IWP is an interbank contract under central bank supervision that allows bank to obtain its claim (which could be created through binding contracts or commercial documents) and its client's claims regarding commercial documents (check, promissory note and bill) after online-depleting the debtor's accounts in the agent bank and the other debtor's accounts in other banks and then the accounts belonging to his guarantors at other bank.

The Central Bank provides the legal and electronic infrastructures for the operation of this protocol. The software of IWP should possess withdrawal capability from debtor accounts. In the case that any money is deposited in one of the accounts of the debtor, at the same time, it will be transferred to the claimer account automatically, and consequently, the transactions under this process are registered in central bank databases and information systems. Moreover, central bank hands over the withdrawal information from debtor's account or gives permission to competent authorities for real-time monitoring and making confidence about the amounts of the debts of debtors before adjudication or legal sentencing.

All included banks and non-banking financial institutions in IWP will create the required preparations for operation of this protocol. It is necessary that every banking customer (including real persons or legal entities) have a Unique Customer Identification Code (UCIC) in the banking system. This code should correspond to customer accounts through the International Bank Account Number (IBAN) ${ }^{3}$. Implementation of this arrangement is determined by the central bank. All checks, promissory notes, and bills must contain a unique serial number as well. Implementation of this subject is arranged by the central bank and is enunciated to banks and financial institutions. UCIC identifier must be published in a specified place on checks, promissory notes, and bills. The debtors and guarantors of the check, promissory note or bill must write down their banking identifier accompanying with other required information on the documents at the time of signing. The manner of this preparation is arranged and enunciated by the ministry of finance with the cooperation of the central bank. It is necessary that finance ministry cooperates with the central bank in compiling the operational regulation of Commercial Act regarding note, bill and check with respect to contents of this protocol and pass it to the legal authorities. The mentioned rule should simplify protest and debt-collection steps of checks, promissory notes, and bills and prepares to collect the claim document from debtor's or his guarantor's accounts in all banks through IWP. Banks by IWP are allowed to collect all claims, which initiated from financial loans, checks, promissory notes or bills at maturity. Banks also obliged to provide required preparations for the collection of his own or customer's claims whose are matured, outstanding, delayed, doubtful or bad debts arising from financial loans, checks, promissory notes or bills through IWP for all claims that have ever been created through the old non-integrated traditional system.

\footnotetext{
${ }^{1}$ See:

Bidabad, Bijan. (2014). New Operational Islamic Banking System, Volume One, Theoretical Foundations, LAP Lambert Academic Publishing, OmniScriptum GmbH \& Co. KG, ISBN: 978-3-659-54463-7.

Bidabad, Bijan. (2014). New Operational Islamic Banking System, Volume Two, Applicational Issues, LAP Lambert Academic Publishing, OmniScriptum GmbH \& Co. KG, ISBN: 978-3-659-55210-6.

2 Rastin Banking Complementary Systems: refer to innovations, systems and complement methods in Rastin Banking

${ }^{3}$ International Organisation for Standardisation. (2003) Banking and related financial services, International Bank Account Number (IBAN). 24 July 2003. Retrieved 11 August 2012.
} 
Ministries and government agencies whose incomes and expenditures are recorded in state budget bill and have specific budget row are not included in withdrawal from debtor's account through IWP. State companies and other affiliated organizations and institutions to government and non-governmental public agencies that do not use government budget as municipalities, insurance, healthcare, pension and social security funds, foundations, and charity and philanthropic institutes are included and subjected to this protocol.

\section{IWP Operational Process}

For IWP implementation, Interbank Withdrawal Protocol Unit (IWPU) at the ACH and Interbank Withdrawal Protocol System (IWPS) under central bank supervision are established and activated. IWPU is responsible for the settlement of claim document from debtor's accounts in the banking system and submits daily electronic reports of the received and paid amounts to the central bank. IWPS is responsible for the whole processes of recording claim documents, withdrawal and funds transfer from debtor's accounts in all banks, authentication of the debtor based upon Unique Banking Customer Identification Code (UCIC) and a notice of withdrawal issuance to banks, management reports, settlement process, and work-in-process management according to defined parameters.

The beneficent of the claim document submits the document to the bank and after authentication and verifying the document, bank issues a receipt in favor of beneficent. The claim document is withdrawn from debtor's accounts in the agent bank. In the case of insufficient balance in all existing accounts of the debtor or his and guarantors in agent bank, the bank submits and loads the image of claim document and banking UCIC and amounts of the claimed funds of claimer to IWPU of ACH through secure communications channels. Claim document including check, promissory note and bill could be withdrawn with respect to authentication standard characteristics and after IT and legal infrastructures preparations and connecting accounts to UCIC through Automatic Clearing House (ACH). The operational process should be designed in a way that all operations are conducted in a secure platform. Bank after authentication of the claimer loads the digital image of claim document into ACH through interactive and IT-based channels; attaches Magnetic Ink Character Recognition (MICR) ${ }^{4}$ code line or Radio-Frequency Identification $(\text { RFID })^{5}$ label and uses digital signatures on the document with asymmetric cryptography. ACH uses the public key of issuing bank for decrypting document signature and makes confidence about document authenticity and accuracy and other fields such as identification codes of the claimer and debtor, then make query ${ }^{6}$ for loading debtor's accounts balance and other financial assets including trust assets or dealing assets like bonds in all banks or nonbank financial institutes. The ACH after getting confidence regarding document authenticity and available data in the received fields -based on central bank permission- send a query about debtor's accounts and other trust financial assets in different banks and non-banking financial institutions to the banks' databases for searching and recognizing debtor's accounts according to the debtor's Unique Customer Identification Code (UCIC) automatically. The balance of all accounts of the debtor in different banks is determined by aggregate function ${ }^{7}$ in the Relational Database Management System (RDBMS) ${ }^{8}$. Accounts balances in various banks are sorted in descending order and are reported to the ACH. ACH makes a withdrawal from the highest balance account to the lowest respectively. In the case of sufficient cash balance and equal possible withdrawal, the amount of claim document is withdrawn in equal amounts from existing accounts and transferred to beneficent accounts in the agent bank through Real Time Gross Settlement System (RTGS) ${ }^{9}$, and the debt documents of banks are submitted through IWPS. In the case of

\footnotetext{
${ }^{4}$ Magnetic Ink Character Recognition (MICR) is a character-recognition technology used mainly by banks to ease the processing and clearance of checks and other documents. The MICR encoding is called MICR line. It is at the bottom of checks and other vouchers and typically includes the document-type indicator, bank code, bank account number, check number, check amount, and control indicator. The technology allows MICR readers to scan and read the information directly into a data-collection device. Unlike barcodes and similar technologies, MICR characters can be read easily by humans. For more information see: Troy group (2010), MICR - Magnetic Ink Character Recognition, What is MICR, http://www.whatismicr.com/index.html

${ }^{5}$ RFID is an automatic authentication technology that uses less energy and short-range electromagnetic wave which increase the ability to access data significantly. For more information refer to following link:

Tektronix, (2004), Radio Frequency Identification (RFID) Overview, http://www.isotest.es/web/Soporte/Formacion/Notas\%20de\%20aplicacion/TEKTRONIX/TEKTRONIX\%20RSA/RFID.pdf

${ }^{6}$ A query is a request for information from a database.

${ }^{7}$ Aggregate function: is a function that performs a computation on a set of values rather than on a single value.

${ }^{8}$ A relational database management system (RDBMS) is a database management system (DBMS) that is based on the relational model as introduced by Codd. What constitutes a relational database system is composed of Codd's 12 rules. E. F. Codd, (1970), A Relational Model of Data for Large Shared Data Banks, IBM's San Jose Research Laboratory http://www.seas.upenn.edu/ zives/03f/cis550/codd.pdf

${ }^{9}$ Real Time Gross Settlement (RTGS) is a banking settlement system for continuous settlement of payments on an individual order basis without netting debits with credits across the books of a central bank.
} 
sufficient cash balance and impossible equal withdrawal from debtor's accounts, the output records of query operations are sorted in descending order. Depletion of debtor's bank accounts is done from high to low amounts. Upon a logical algorithm, the system starts to withdraw the amount of the claim document from debtor's accounts and consequently transfer it to claimer's account through Real Time Gross Settlement (RTGS) system. Withdrawal figure from banking accounts is informed to the bank. In the case of insufficient balance in debtor's accounts in all banks, depletion of accounts is carried out, and insufficient cash balance deficit certificate is issued by banks and delivered to the claimer; thereby he can obtain his claim through Enforcement of the Purports of Binding Banking Documents Unit in Rastin Bank ${ }^{10}$ or judicial proceedings in court. By the client's request, withdrawal operation could be repeated at frequent intervals until the debt is collected. The whole procedure is shown in figure 1.

Regarding the above process, the priorities of debtor accounts for withdrawal operations are performed on current deposit account first and then, saving deposit account, time deposit account from low to high time-longitudes respectively, and then on other accounts, bonds, and foreign exchange accounts according to the cited priorities for domestic currency. Regarding withdrawal from time deposit investment accounts including local and foreign exchange currencies, primarily bank blocks the account equal to the claim and withdrawal operation from the accounts is delayed for 10 days. The debtor is noticed in appropriate ways. If the debtor pays his debt within the specified period, the bank unblocks the blocked deposit.

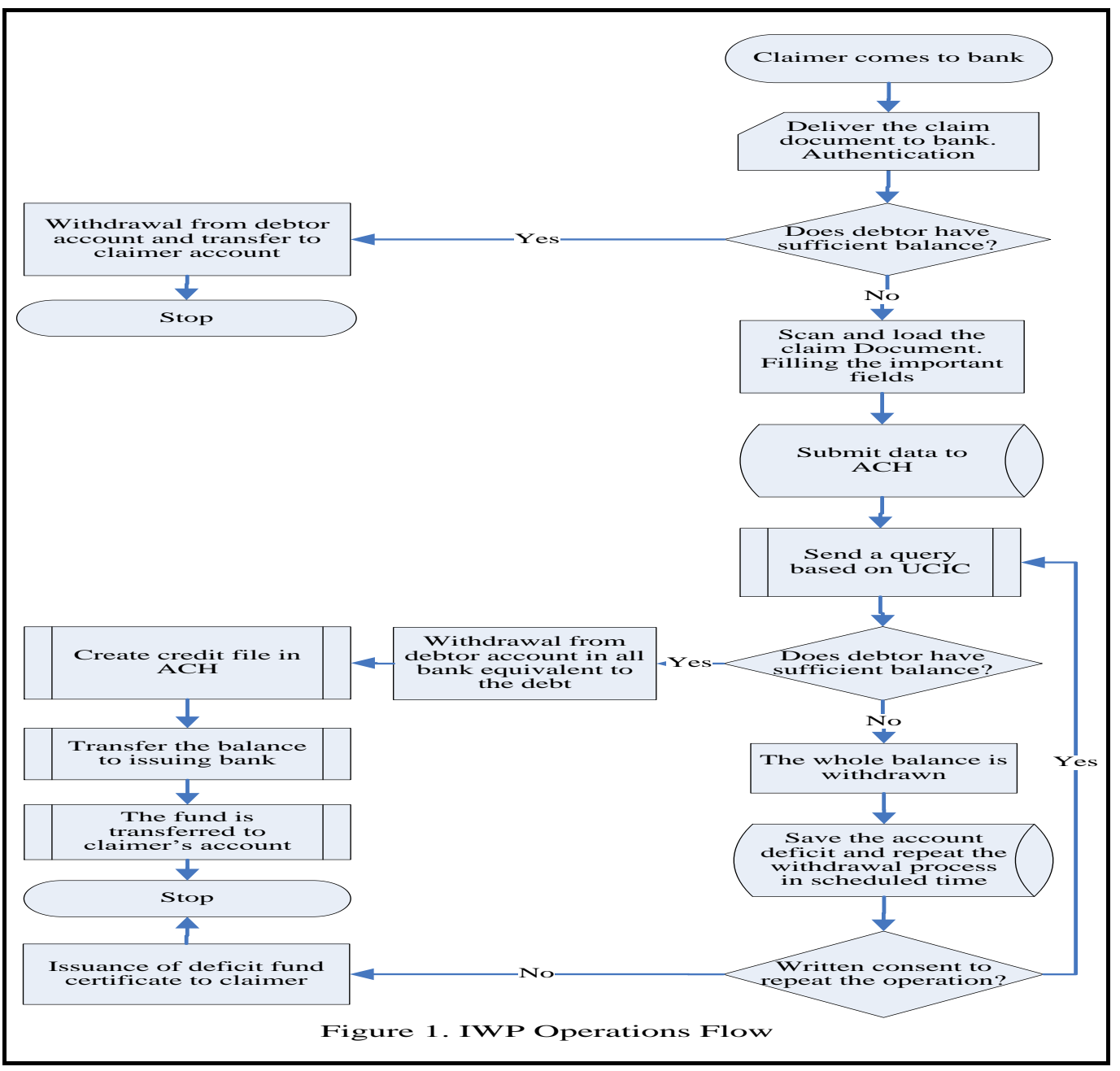

${ }^{10}$ Bijan Bidabad, Saeed Abdullahi, Mahshid Sherafati. (2016) Enforcement of the Purports of Binding Banking Documents in Rastin Banking - Part I. International Journal of Law and Management, Emerald Group Publishing Limited, Vol:59, Iss:1. Bijan Bidabad, Saeed Abdullahi, Mahshid Sherafati. (2016) Enforcement of the Purports of Binding Banking Documents in Rastin Banking - Part II. International Journal of Law and Management, Emerald Group Publishing Limited, Vol:59, Iss:2. 


\section{References}

Bidabad, Bijan. (2014). New Operational Islamic Banking System, Volume One, Theoretical Foundations, LAP Lambert Academic Publishing, Omni Scriptum GmbH \& Co. KG, ISBN: 978-3-659-54463-7.

Bidabad, Bijan. (2014). New Operational Islamic Banking System, Volume Two, Applicational Issues, LAP Lambert Academic Publishing, OmniScriptum GmbH \& Co. KG, ISBN: 978-3-659-55210-6.

Bidabad, Bijan, Saeed Abdullahi, Mahshid Sherafati. (2016) Enforcement of the Purports of Binding Banking Documents in Rastin Banking - Part I. International Journal of Law and Management, Emerald Group Publishing Limited, Vol:59, Iss:1.

Bidabad, Bijan, Saeed Abdullahi, Mahshid Sherafati. (2016) Enforcement of the Purports of Binding Banking Documents in Rastin Banking - Part II. International Journal of Law and Management, Emerald Group Publishing Limited, Vol:59, Iss:2.

Bidabad, Bijan (2018), General Regulatory Framework in Rastin Profit and Loss Sharing Banking (Part IOperational Context). Journal of Business and Finance in Emerging Markets, JBFEM, [S.1.], v. 1, n. 1, p. 1126, May. ISSN 2580-5568.

https://doi.org/10.32770/jbfem.vol111-26

http://www.bidabad.com/doc/rastin-regulatory-en-I.pdf

Bidabad, Bijan (2018), General Regulatory Framework in Rastin Profit and Loss Sharing Banking (Part II-Legal Groundwork). Journal of Business and Finance in Emerging Markets, JBFEM, JBFEM, [S.l.], v. 1, n. 2, p. 109-126, Nov. ISSN 2580-5568.

https://doi.org/10.32770/jbfem.vol1109-126

http://www.bidabad.com/doc/rastin-regulatory-en-II.pdf

Bidabad, Bijan (2019), General Regulatory Framework in Rastin Profit and Loss Sharing Banking (Part IIIAuxiliary Provisions). Journal of Business and Finance in Emerging Markets, JBFEM, May, Vol 2, No. 1, pp. 51-65. ISSN 2580-5568. https://doi.org/10.32770/jbfem.vol251-66 http://www.bidabad.com/doc/rastin-regulatory-en-III.pdf

Codd, E. F. (1970), A Relational Model of Data for Large Shared Data Banks, IBM's San Jose Research Laboratory. http://www.seas.upenn.edu/ zives/03f/cis550/codd.pdf

International Organisation for Standardisation. (24 July 2003) Banking and related financial services, International Bank Account Number (IBAN).

Tektronix, (2004), Radio Frequency Identification (RFID) Overview, http://www.isotest.es/web/Soporte/Formacion/Notas\%20de\%20aplicacion/TEKTRONIX/TEKTRONIX\%20R SA/RFID.pdf

Troy group (2010), MICR - Magnetic Ink Character Recognition, What is MICR. http://www.whatismicr.com/index.html

\section{Copyrights}

Copyright for this article is retained by the author(s), with first publication rights granted to the journal.

This is an open-access article distributed under the terms and conditions of the Creative Commons Attribution license (http://creativecommons.org/licenses/by/4.0/) 